\title{
Editorial
}

\section{Launching Implementation and Replication Studies in Mathematics Education (I RME)}

\author{
Uffe Thomas Jankvist | ORCID: 0000-0002-4089-0242 \\ Danish School of Education, Aarhus University, Aarhus, Denmark \\ utj@edu.au.dk
}

Mario Sánchez Aguilar | ORCID: 0000-0002-1391-9388

CiCATA Legaria, National Polytechnic Institute, Mexico City, Mexico

mosanchez@ipn.mx
Morten Misfeldt | ORCID: 0000-0002-6481-4121
Department of Science Education, University of Copenhagen, Copenhagen, Denmark misfeldt@ind.ku.dk

Boris Koichu | ORCID: 0000-0001-7298-8175

Department of Science, Weizmann Institute of Science, Rehovot, Israel boris.koichu@weizmann.ac.il

\section{$1 \quad$ Hoist the Flag!}

We are launching a new international research journal in mathematics education.

"What?", you might ask, “Doesn't mathematics education already have a myriad of journals?"

Yes, this is indisputable. A quick count will easily reveal more than a hundred, counting also regional and national journals. Yet, as the title of this 
journal reveals, Implementation and Replication Studies in Mathematics Education (IRME) is a specialized journal. A journal that is concerned with two of our field's areas, implementation and replication, which have not previously received sufficient attention. And this is despite the fact that attention has been called to these areas for almost as long as the research field of mathematics education has existed. For example, Maxim Bruckheimer already called for more "creative implementation" in 1979, and Phillip M. Eastman asked and attempted an answer to the question of "replication studies: why so few?" as far back as in 1975 .

Now, you might say: "But if these types of studies haven't gained momentum during the last fifty years, why should they now?"

There is more than one answer to this question, we believe. One answer is that mathematics education as a research field now may be more 'ripe' and ready for such studies than it was a few decades ago. As an emerging discipline in the late 1960s, 1970s and even well in the 1980s, mathematics education research spent much energy on becoming accepted as a scientific discipline in its own right (e.g., Biehler et al., 1994). Much attention was given to the problem of justifying its existence as a research domain (e.g., Sierpinska \& Kilpatrick, 1998). This also involved the development of its own theoretical constructs, frameworks, and distinctions as well as establishing research methodologies to fit the mathematics education challenges at hand. By now, 2021, there are simply more results and findings concerning the teaching and learning of mathematics that can be implemented in practice. There are more large-scale initiatives of implementation around to study; and there is now a multitude of research results and findings to use as objects of replication studies. Another answer, which hopefully will turn out to be of equal importance, is that now - unlike fifty years ago - we have a dedicated outlet to exactly these types of mathematics education studies.

Nevertheless, we will be breaking new ground as we move forward. These advances are fundamental since the areas of implementation research and replication studies in mathematics education are still in their cradle. We thus invite our fellow researchers in mathematics education to take part in nourishing these research areas and in shaping them in their youth, by conducting research within them and by reporting on them in this journal. Such endeavor will comprise both theoretical as well as empirical studies. A few handfuls of researchers have already accepted this challenge by writing papers for this first issue, and for that we are grateful. Other researchers from our field have accepted to be part of this imminent journey by joining the Editorial Board of the journal. We thank all of them and look forward to fruitful collaborations in the near future. 
Each paper published in IRME will have a so-called "impact sheet" associated with it. These sheets are available online (open access) and not in the printed version of the journal. An impact sheet is a 1-2 page short and easyto-read description of the potential "impact" that the publication may be thought to have on practice. The idea is that this will allow better dissemination of knowledge in the form of key findings and learnings from the journal, made readily available to stakeholders and practitioners, who work with practical and organizational issues of implementation. The form of these impact sheets may further develop over time as the journal grows. The impact sheets are restricted to digital publication on Figshare (with a link to the Impact sheet in the pdf of the corresponding article), so that they may be revised or amended over time. One can imagine that the journal authors may be able to keep on reporting on the actual impact of their research papers/studies for $5^{-10}$ years after publication, and that this could be mentioned in the revised versions of the original impact sheets. The construct of an "impact sheet" is new in mathematics education research, and we are bound to make it up as we go along. Yet, we shall do so in close collaboration with the researchers who publish in IRME.

In this editorial of the first issue of IRME, we first dig a little deeper into discussions surrounding research in the areas of implementations and replications, and into how we envision these, both as researchers and as editors of this new journal. We do this in the following sections, while also providing introductions to the four papers included in the first issue.

When Does Implementation Enter into the Picture?

Niss (1996) identified three problems for mathematics education in society. First, the justification problem which is about reasons, motives and arguments for providing mathematics education to various categories of students, i.e. the question of "why". Having dealt with this first problem, the next one is the possibility problem, which concerns if it is possible to provide such mathematics education to these students, satisfying what is expressed by the "why" question. Having dealt with both of these problems, the implementation problem comes to the foreground.

[The implementation problem] deals with establishing the structural and organizational framework within which mathematics education is to take place. It further deals with providing the immaterial resources (e.g., content, curricula, pedagogy, teaching methods, teacher education, working 
forms), the human resources (teachers, consultants, mathematics educators) and the material resources (classrooms, textbooks, technology) for the realization of mathematics education. The implementation problem also includes issues related to the philosophy and modes of assessment. In other words, the implementation problem focuses on the questions of "how?" and "what?" (p. 374)

This is also evident from the previously mentioned text by Bruckheimer (1979), who addresses curricula. Based on examples from US, UK and Israel, he states:

Generally, curricula are not implemented. Or as the mathematician might put it, the order of magnitude of implementation is less than $\varepsilon-$ and as everyone knows, $\varepsilon$ may be chosen arbitrarily small.... Teachers are essentially teaching the same way that they were taught in school. Almost none of the concepts, methods, or big ideas of modern mathematics programs have appeared in this median classroom. (p. 43)

Bruckheimer (1979) continues to argue that implementation should not be conceived as a static process of implementing what is already created. Rather it should be regarded as dynamic, and that curricula should evolve over time through manipulation, adaption and additions. Hence, the actual implementations should themselves become creative. "The more complex (innovative) the products of curriculum development, the more complex the problem of implementation." (p. 45).

To some extent this ties in with more recent claims concerning the theorypractice relationship, provided in an editorial of the Journal for Research in Mathematics Education (JRME) by Cai et al. (2017). Here, it is argued that researchers often regard implementation as a separate process-separate from designing and testing an intervention. This is despite the fact that in recent years, researchers have to a larger extent come to regard implementation as a phenomenon in its own right, which should be seen together with a recognition, emerging during the 1980 os (Schoenfeld, 2016), that educational inventions need to be followed into the classrooms. Cai et al. (2017) report on a story by Gravemeijer and colleagues (2016) as being especially telling of what may happen when researchers are integrally involved in the development of and researching into a curriculum involving careful support for teachers, but leaving the actual implementation of this as a follow-up task for the teachers. The intended learning goals were unrealized, because the attention shifted during the implementation "toward procedures that generated answers for specific tasks" (p. 39), which happened at the expense of the intended level of advanced conceptual understanding. Furthermore, this made clear the "gap" 
between research and practice that exists - in this case between intended and enacted curriculum. Cai and his fellow editors state:

The point we wish to make in this editorial is that including studies of implementation might not be enough. If researchers hope to impact practice, they might need to embed implementation as an inseparable aspect of intervention design. If researchers leave implementation to teachers, or if they study implementation as a phenomenon separate from the design of an intervention (e.g., writing and testing curricula), they could miss a chance to boost the impact of their work. (p. 344)

Yet, Cai et al. (2017) do state that "Clearly, issues of implementation are no longer being ignored." (p. 344). This is true-several recent new initiatives confirm this.

One was the establishment of a Thematic Working Group (TWG 23) at the 1oth Congress of ERME (European Society for Research in Mathematics Education) on "Implementation of research findings in mathematics education" (Jankvist et al., 2017). The originators of this initiative described their motivation for creating this TWG in terms of wanting to create a forum dedicated to discussing activities on "putting previous empirical results and findings as well as theoretical constructs based on these to good use in mathematics classrooms, mathematics programs, mathematics teacher education, in-service teacher training, etc." as well as a wish to research "ongoing developmental projects that rely heavily on previously documented research results" in order to "advance the 'implementation research' aspects of our activities" (p. 3769). All of the editors of IRME have been involved in the work of this TWG (Aguilar et al., 2019), and the journal may thus be seen as a natural continuation of part of the work in the TwG.

Other initiatives that confirm the presence of issues of implementation in the minds of mathematics education researchers include special issues in major international journals in our field. One was a special issue of Educational Studies in Mathematics (ESM) on "different ways to large scale implementation of innovative teaching approaches" edited by Maass, Cobb, Krainer and Potari (2019). Another example is the upcoming special issue of $Z D M$ on "implementation and implementability of mathematics education research" edited by a Koichu, Aguilar and Misfeldt (2021). While the ESM special issue had a direct focus on the matters of scaling up as part of the implementation problem, the ZDM special issue has a broader focus. Nevertheless, it is evident from its papers that scaling up is an inseparable element in the discussion of implementation, as we shall touch on below. 
What implementation research in mathematics education is considered to be, and what it will continue to be, is a topic of discussion. The original vision of the CERME TWG was phrased as follows:

We want to explore a wide variety of 'good examples' of implementing research findings and results (back) into practice in order to improve the teaching and learning of mathematics at all educational levels on a research-based foundation. Over time we may begin to look into the aspects of research on implementations, potential requirements for these to function, etc.

JANKVIST ET AL., 2017, p. 3774

Although related, this vision indicates a distinction between the work associated with translating research findings and results from mathematics education research into a format suited for practice, and work associated with researching actual (large scale) implementations. Looking into some of the literature outside of mathematics education research, such as implementation research in health science, Nilsen (2015) distinguishes three overarching aims when it comes to theoretical approaches used in so-called implementation science: (1) describing and/or guiding the process of translating research into practice; (2) understanding and/or explaining what influences implementation outcomes; and (3) evaluating actual implementations. A (working) definition of implementation research in education has been provided by Century and Cassata (2016):

Implementation research, by our working definition, is the systematic inquiry of innovations enacted in controlled settings or in ordinary practice, the factors that influence innovation enactment, and relationships between innovations, influential factors, and outcomes. Thus, frameworks that inform the organization of implementation research address two main concerns- how to conceptualize and describe the innovation itself, and how to identify and organize the contexts, conditions, and characteristics that influence innovation enactment (influential factors). These two fundamental concepts-(a) characteristics of the innovation and (b) influential factors - are basic elements of varied theories of change and a key part of most recent research syntheses or metaframeworks depicting innovations in context. (p. 181) 
From this quote, we may already deduce a few central terms that are bound to be of importance also for implementation research in mathematics education, i.e. "innovation" and "influential factors". In relation to innovation, Rogers' (1962) "Diffusion of Innovations" is often provided as reference. Yet, with the discussion of innovation, come the questions of novelty of the innovation, and of novelty for whom? Associated with the discussion of innovation, is the discussion of "value", for instance, an innovation is only an innovation if it creates value for some stakeholders (Krainer, 2014). Who are the "stakeholders" of a given innovation in mathematics education then? Notice that they need not necessarily be the end users, such as the teachers or the students (e.g., Jankvist et al., 2021). In order to evaluate the effect of the implementation of some innovation, it must be possible to measure "change". Hence, change is also a central element, and the question then becomes how to measure the desired change. This is where mathematics education research may come into the picture, since "the parameters on which to measure change may oftentimes be found within theoretical constructs from mathematics education itself" (Jankvist et al., 2019, p. 4410).

What we have discussed above ties in with Nilsen's (2015) third aim, i.e. evaluating implementations, which outside of mathematics education is related to the field of "theory-driven evaluations" (e.g. Chen, 1990, 2015). When it comes to addressing influential factors, Nilsen's second aim distinguishes between "enablers" and "barriers" (for an example in mathematics education, see Gregersen et al., 2019). As for Nilsen's first aim of translating research into a form suitable for practice, among other things, this has to do with the potential "implementability" of research results-one of the themes addressed in the upcoming ZDM special issue (Koichu, Aguilar \& Misfeldt, 2021).

At the previous CERME, the TWG on implementation offered a definition of implementation in the spirit of socio-cultural perspectives:

Implementation is a change-oriented process of adapting and enacting a particular resource (e.g., an idea, a tool, an innovation, a framework, a theory, an action plan, a curriculum, a policy) that occurs in partnership of two communities, a community of the resource proponents (CRP) and a community of the resource adapters (CRA). These communities differ but can intersect. At the beginning of the process, the CRP has the ultimate agency over the resource. The process of adapting a resource by CRA includes some of the following: (1) constructing an agency over the resource, (2) changes in ways of communicating, and (3) changes in practice.

AGUILAR ET AL., 2019, p. 4362 
This definition will be further refined in Koichu et al. (2021). Connecting this definition with the argument by Cai et al. (2017), researchers in mathematics education should thus not limit themselves to the CRP, but make sure to work closely with the CRA in order to overcome the "gap" between research and practice by generating possibilities for "creative implementation" as has been envisioned by Bruckheimer (1979).

As mentioned, the issue of scaling up is closely related to implementation research in mathematics education (e.g., Maass et al., 2019; Roesken-Winter et al., 2021). Almost 20 years ago, Burkhardt and Schoenfeld (2003) argued that the "profitable dialectic between theory and practice can and should occur ... from the initial stages of design all the way through robust implementation on a large scale" (p. 5). In a more recent publication of the ZDM special issue, they argue that although so-called "existence-proofs" are valuable, also from an implementation perspective, "implementability should surely aim to mean implementation on a significant scale" (Burkhardt \& Schoenfeld, 2020, p. 12). According to Levine and Cooper (1991), however, "implementability" of an innovation in an educational context is the indication of how realistic and feasible it is for practitioners to implement; a definition which does not address the issue of scaling up as such. We only point this out to illustrate that the issue of scaling up is up for discussion as part of the ongoing process of conceptualizing implementation research both inside and outside of mathematics education. As editors of IRME, we are not going to take a definite stance in this debate. Rather we invite our colleagues to see IRME as the natural habitat of discussions of the intricacies of implementation research. We thus welcome all serious and relevant research papers addressing aspects of implementation research. As already stated in our call for papers for IRME, examples of topics include:

- Studies that analyze how the results produced in the field of mathematics education research can be implemented into educational practice.

- Studies focused on analyzing and/or comparing the functioning and outcomes of actual implementation initiatives.

- Studies investigating mathematics instruction at scale and studies exploring implementation strategies for scaling up learning initiatives.

- Methodological studies that elucidate the way in which different theories, methods and tools can be used to develop implementation research.

\section{4 Two Papers on Implementation Research in the First Issue of IRME}

This first issue of IRME includes two papers that make contributions of different nature to the development of implementation research in mathematics education. 
The paper by Michèle Artigue (2021) takes the problem of conceptualizing implementation research in mathematics education as a starting point, but rather than searching for theoretical constructs outside the discipline of mathematics education, it starts from within. In a sense, this is an obvious approach since the implementation problem has been around since the beginning of mathematics education research.

The theoretical resources in focus originate in design-based research (DBR), in the systemic and ecological perspective underlying the anthropological theory of the didactic (ATD), and in the documentational approach to didactics (DAD) regarding the teachers' relationship with educational resources. From DBR, the main constructs considered are the hypothetical learning trajectory (HLT) that mediates between both theory and practice and between intentions and observations, and collaborative structures between researchers and teachers from cooperative engineering. From ATD, the levels of didactic codeterminacy and the two different paradigms of questioning the world and the dominant-yet less progressive paradigm of visiting works. From DAD, Artigue (2021) highlights the language for discussing technology and resource use in relation to mathematics education with specific focus on the teachers.

The paper then examines particular examples of implementation studies, from the PRIMAS project and from the TWG on implementation of research findings in mathematics education at CERME 10 and CERME 11. Artigue (2O21) makes the observation that the way implementation is conceptualizd in the PRIMAS project and in many of the papers of the TWG at CERME is not building on the resources suggested in the first half of her paper. This points to work ahead, i.e. by combining internal mathematics education theories, external theoretical constructs, and empirically generated concerns in large scale and implementation focused projects.

The above quoted definition by Century and Cassata (2016) proposes that implementation research attends to "how to identify and organize the contexts, conditions, and characteristics that influence innovation enactment" (p. 181). Paul Cobb and Kara Jackson (2021) present exactly this type of empirical research in their paper. In addition, their study explicitly attends to the scaling-up problematics.

They present a long-term comprehensive effort to implement a particular innovation-equity-driven, inquiry-oriented mathematics instruction-in four large urban districts in the US. In a way, they exemplify how a relatively small research team may deeply explore and usefully inform large-scope implementations. They achieve this by conducting a comprehensive set of design-research studies on the implementation processes in focus schools, and by operating with either quantitative or qualitative data. This enacted design-research-based approach enabled the scholars to develop in-depth 
understanding of the implementation processes and to communicate this understanding in the form of recommendations, $67 \%$ of which were acted upon in the districts. By all means, this is an inspiring example of fruitful research-practice partnership.

Based on the eight-year-long implementation research as an example, Cobb and Jackson (2O21) propose an empirically grounded theory of action consisting of three top-level components: a coherent instructional system, school leaders' practices as instructional leaders in mathematics, and district leaders' practices in supporting the development of school-level capacity for instructional improvement. The first component-a coherent instructional system-is the main theme of the paper.

Have Replication Studies Not Always Been Around?

The interest in replication studies has been around since the first years in which mathematics education has existed as a field of research. To the best of our knowledge, the first replication study published in a mathematics education research journal is the work of Peterson et al. (1973), that appeared in JRME. This paper reports on three independent replications of Peterson's (1971) study on the effect of organizers and the knowledge of a behavioral objective on the learning and retention of a mathematical concept. The purpose of the three replication studies reported in Peterson et al. (1973) was to test the hypothesis that the learning and retention of a mathematical concept can be facilitated by providing the learner with an advance organizer (AO), a post organizer ( $\mathrm{PO}$ ), or knowledge of the behavioral objective (кво). Here АО, РО and кво refer to different types of information provided to the learner before and after mathematical instruction.

However, the idea of having a space for replication studies in a mathematics education journal has emerged prior to the empirical work of Peterson et al. (1973). In a letter to the JRME editor, George W. Bright suggests to the JRME Editorial Board the addition of a journal department dedicated to replication studies, which could be modeled after the "Replications and Refinement" section of the Journal of Social Psychology (see Bright \& Romberg, 1972, p. 19o). According to George W. Bright, the replication reports published in this department "would refine current techniques or replicate known procedures in order to verify or refute previous findings." (p. 19o). Bright argues that the cumulative results produced by replication studies might aid in establishing well-founded theory. However, as he himself acknowledges, the accumulation of results and findings through replication studies is not always an easy task: "Accumulating 
the supporting or refuting evidence from such replications is at best haphazard, and more often, impossible" (p. 19o). Thus, George W. Bright argues that a department on replications at JRME: "would aid in organizing the reporting of replications, thus increasing the chance of synthesizing common findings." (p. 190).

The JRME Editorial Board seriously discussed this recommendation. Even though the Board agreed with the rationale and expressed an interest in receiving and publishing such manuscripts, it concluded at that time that JRME did not need a special section or department for this kind of papers. These documents could fit into the existing sections of the journal:

Depending upon the substantive nature and significance of the research, the paper might well be submitted as a regular article. Or, if submitted in some reduced form ... the paper could be considered as a "Forum" article ... In the event the researcher merely wishes to make a brief statement regarding the results of a replication or refinement of a study published in JRME he might consider a "Letter to the Editor."

BRIGHT \& ROMBERG, 1972, p. 190

Other voices, such as Eastman's (1975), joined Bright's to argue the importance of promoting replication studies in mathematics education and the need to have a specific space to publish them:

I would like to see the Editorial Board reevaluate that decision and create the new department. Surely, with a department of the Journal devoted to "Replications and Refinements," we would find researchers more willing to conduct or report the findings of these types of studies.

EASTMAN, 1975, p. 68

Probably because of the youth of the field, and despite these expressions of interest, a space dedicated particularly to replication studies was not established. Neither in JRME, nor in any other mathematics education journal. Although in subsequent decades there have been reports of replications in mathematics education (e.g., Beattie, 1995; De Bock et al. 2011; Jacobson \& Simpson, 2019; Star et al., 2011), some statistics suggest that the number of replication studies published in mathematics education in recent years is low (Cai et al., 2018).

So, here we are, almost fifty years after Bright's letter to the JRME editor, materializing the idea of having a publishing space dedicated specifically to replication (and refinements) studies in mathematics education. It seems 
that after five decades the field of mathematics education research is still at a development stage, where there is a growing interest in the pursuit of replication studies. Such an interest is reflected in the specialized groups that have emerged in some academic conferences of our discipline (Aguilar et al., 2019; Inglis et al., 2018), and in the recent publication of studies related to replication in mathematics education (see, for example, JRME volume 49, number 1, published in 2018). We hope that IRME can be a space of expression for all our colleagues already interested in the development of replication studies, and that it may spark the curiosity of other scholars interested in exploring this area of research.

\section{What Are "Valuable" Replications?}

In somewhat simplified terms, we can say that a replication is the repetition of a study that has been peer reviewed and perhaps published in a specialized outlet. However, not all replications profess to accurately reproduce the original study. Particularly in social sciences, including mathematics education, it would be difficult —if at all possible - to reproduce, for instance, the complex interactions that take place in a mathematics classroom. It is here that educational researchers have made use of the notion of conceptual replication, which refers to a type of replication in which the original study is reproduced while intentionally modifying some of its variables. It is of course an open discussion in the field of mathematics education "how far" a replication can be from the original study in order to continue to be considered a conceptual replicationsee for instance Star's (2021) discussion in this issue.

The importance of replications in mathematics education has been argued from different angles. It has been claimed that replications can help us verify or refute previous research findings (Bright \& Romberg, 1972); that they provide us with comprehension of the conditions that make a particular research finding true or not (Cai et al., 2018); that they help us guard against contextspecific results and provide us with additional assurance of implied generality (Schoenfeld, 2018); and that they are essential for generalizing from a small population to a larger population (Thanheiser, 2018), among other arguments.

Despite the apparent agreement on the importance of replication studies in mathematics education, there are different opinions-some of them opposing - about what might be a valuable replication. The discussion covers various aspects related to the quality of a replication and the studies that are worth replicating and publishing. For instance, some researchers find internal replications problematic, because there may be issues of reliability and conflict of interest when one of the researchers from the original study also 
participates in the replication (Jacobson \& Simpson, 2019; Schoenfeld, 2018). Other researchers, instead, argue in favor of internal replications. A researcher who participated in the original study can provide the replication study with insider knowledge. This kind of knowledge might enable the researchers to faithfully replicate the original study by accounting for unintentional variation that might be introduced by a researcher in an external replication (Melhuish \& Thanheiser, 2018). It has also been argued that valuable replication studies are those that convincingly show that there is a reason to test the generalizability or validity of the original study's results as being valuable (Melhuish \& Thanheiser, 2018), or that make a convincing case that the field will learn something significant from the replication that is not already known (Star, 2018).

At IRME, we offer an open and plural stance towards replication studies in mathematics education. This means that we are open to receiving reports of external and internal replications aiming at different purposes (see Van Der Auwera et al., 2021, in this issue for an example of an internal conceptual replication). We are also interested in receiving theoretical contributions on replication-related issues in mathematics education. Our call for papers provides more details of some of the kinds of manuscripts that we are willing to receive:

- Replication studies in which previous research findings (empirical and/or theoretical) can be tested for validity, generality or be explored to find the conditions under which they do or do not hold.

- Replication studies where previous research findings are (re)interpreted using different or new theoretical perspectives to expand our understanding of the original results.

- Replication studies investigating the effects of a particular educational intervention under different conditions, contexts, or sample populations.

- Methodological studies that elucidate the way in which different theories, methods and tools can be used to develop replication research.

We would like IRME to be a forum where ideas related to replication in mathematics education are tried out, and findings based on replication studies are presented and discussed. We are convinced that replication studies can enrich and complement the very way the knowledge is produced and accumulated in the field of mathematics education.

\section{7 Two Papers on Replication Studies in the First Issue of IRME}

This first issue of IRME includes two papers that make contributions of different nature to the development of replication studies in mathematics education. 
As previously noted, there is an open discussion on how much the research design of a replication might deviate from the original study and still continue to be considered a conceptual replication. The paper by Jon R. Star (2021) enriches this discussion by presenting a critical reflection on the origin of the notion of conceptual replication, and the way in which this notion has been interpreted in the field of mathematics education. Star argues that the notion has been interpreted too broadly, generating confusion about how different the methods of a conceptual replication can be from the original study in order to still be considered a replication. Additionally, Star (2021) proposes a conceptual distinction between a replication study and a follow-up study. This distinction could potentially help differentiate the conceptual replications from those studies that are not subject to most of the methodological constraints of the original study.

In addition to advancing the discussion on what counts as a conceptual replication in mathematics education research, Star (2021) also considers what it might take for the field of mathematics education to become a more replication-friendly culture. This is a theoretical paper that contributes to the delineation of key notions for replication studies, but that also promotes the awareness of the mathematics education research community about the importance of this kind of studies for the advancement of our field of study.

The paper by Stijn Van Der Auwera, Lien Mathys, Bert De Smedt, Joke Torbeyns and Lieven Verschaffel (2021) addresses the issue of adaptive expertise in the specific domain of multi-digit subtraction through an internal conceptual replication of the study by Torbeyns et al. (2018).

Van Der Auwera et al. (2021) acknowledge the criticisms that have been made to internal replications in mathematics education (e.g., Jacobson \& Simpson, 2019; Schoenfeld, 2018). However, they promote the validation of their empirical results by external researchers. They do this by providing a detailed description of the methods used in the replication study, including a clear distinction of the methodological changes made to the methods used in the original study of Torbeyns et al. (2018). Additionally, the authors of this paper provide us with supplementary material that includes the items, the questionnaire, and the script that were used during the data collection. Furthermore, to promote the Open Science initiative, the authors also shared the dataset that they collected and analyzed for the replication study.

As editors of IRME we celebrate the openness of Van Der Auwera et al. (2O21), which contributes to establishing a culture of transparency and data sharing necessary for replication studies to flourish. With the support of Brill, we have decided to publish these supplemental materials as part of the replication 
paper. We invite other potential authors to replicate these principles of transparency and data sharing.

\section{Acknowledgements}

We should like to thank all the people at Brill, who made the launch of this new journal possible. In particular, we thank Evelien van der Veer, whom we have worked closely with for the past year in preparing all aspects of setting up the new journal. We also thank Natalie Rieborn, who initially put us in contact with the people at Brill, and who has been a valuable sounding board in different aspects of proposing a new journal. Last, but not least, we also extend our sincere gratitude to all our colleagues, who immediately acknowledged the importance of this new journal and accepted our invitation to join the IRME Editorial Board. Special thanks to the authors of the papers in this first issue of the journal. Thanks to the reviewers of these papers. Both reviews and revisions were conducted on a very tight time schedule. Nevertheless, with good planning ahead and hard work on all sides, everything has come together beautifully and resulted in four very interesting papers for the launch of IRME. A special thanks also to the Editorial Board member Anna Baccaglini-Frank for providing constructive feedback on this editorial.

\section{References}

Aguilar, M. S., Kuzle, A., Wæge, K. \& Misfeldt, M. (2019). Introduction to the papers of TWG23: Implementation of research findings in mathematics education. In U. T. Jankvist, M. van der Heuvel-Panhuizen \& M. Veldhuis (Eds.), Proceedings of the Eleventh Congress of the European Society for Research in Mathematics Education (pp. 4355-4362). Freudenthal Group \& Freudenthal Institute; Utrecht University; ERME.

Artigue, M. (2021). Implementation studies in mathematics education: What theoretical resources? Implementation and Replication Studies in Mathematics Education, 1(1), 21-52. https://doi.org/10.1163/26670127-12341235.

Beattie, K. (1995). Training in the law of large numbers and everyday inductive reasoning: A replication, with implications for statistics course design. International Journal of Mathematical Education in Science and Technology, 26(6), 795-808. https://doi.org/10.108o/002073995026o6o2.

Biehler, R., Scholz, R. W., Sträßer, R. \& Winkelmann, B. (Eds.). (1994). Didactics of mathematics as a scientific discipline. Kluwer. 
Bright, G. W. \& Romberg, T. A. (1972). Letters to the Editor. Journal for Research in Mathematics Education, 3(3), 190-191. https://doi.org/10.5951/jresematheduc .3.3.0190.

Bruckheimer, M. (1979). Creative implementation. In P. Tamir, A. Blum, A. Hofstein \& N. Sabar (Eds.), Proceedings of the Bat-Sheva Seminar on curriculum implementation and its relationships to curriculum development in science (pp. 43-49). The Weizmann Institute of Science.

Burkhardt, H. \& Schoenfeld, A. H. (2003). Improving educational research: Toward a more useful, more influential, and better-funded enterprise. Educational Researcher, 32(9), 3-14. https://doi.org/10.3102/0013189Xo32009oo3.

Burkhardt, H. \& Schoenfeld, A. H. (2020). Not just "implementation": The synergy of research and practice in an engineering research approach to educational design and development. ZDM Mathematics Education. https://doi.org/10.1007/ s11858-020-01208-z.

Cai, J., Morris, A., Hohensee, C., Hwang, S., Robison, V. \& Hiebert, J. (2017). Making classroomimplementationan integralpart of research.JournalforResearch inMathematics Education, 48(4), 342-347. https://doi.org/10.5951/jresematheduc.48.4.0342.

Cai, J., Morris, A., Hohensee, C., Hwang, S., Robison, V. \& Hiebert, J. (2018). The role of replication studies in educational research. Journal for Research in Mathematics Education, 49(1), 2-8. https://doi.org/10.5951/jresematheduc.49.1.0oo2.

Century, J. \& Cassata, A. (2016). Implementation research: Finding common ground on what, how, why, where, and who. Review of Research in Education, 4O(1), 169-215. https://doi.org/10.3102/oo91732X16665332.

Chen, H. T. (1990). Theory-driven evaluations. Sage.

Chen, H. T. (2015). Practical program evaluation: Theory-driven evaluation and the integrated evaluation perspective (2nd ed.). Sage.

Cobb, P. \& Jackson, K. (2021). An empirically grounded system of supports for improving the quality of mathematics teaching on a large scale. Implementation and Replication Studies in Mathematics Education, 1(1), 77-110. https://doi .org/10.1163/26670127-12341239.

De Bock, D., Deprez, J., Van Dooren, W., Roelens, M. \& Verschaffel, L. (2011). Abstract or concrete examples in learning mathematics? A replication and elaboration of Kaminski, Sloutsky, and Heckler's study. Journal for Research in Mathematics Education, 42(2), 109-126. https://doi.org/10.5951/jresematheduc.42.2.0109.

Eastman, P. M. (1975). Replication studies: Why so few? Journal for Research in MathematicsEducation,6(2),67-68.https://doi.org/10.5951/jresematheduc.6.2.0067.

Gravemeijer, K., Bruin-Muurling, G., Kraemer, J.-M. \& van Stiphout, I. (2016). Shortcomings of mathematics education reform in The Netherlands: A paradigm 
case? Mathematical Thinking and Learning, 18(1), 25-44. http://doi.org/10.1080/109 86065.2016.1107821.

Gregersen, R. M., Lauridsen, S. D. \& Jankvist, U. T. (2019). Operationalizing implementation theory in mathematics education research-Identifying enablers and barriers in the Swedish 'Boost for Mathematics'. In U.T.Jankvist, M. van der Heuvel-Panhuizen \& M. Veldhuis (Eds.), Proceedings of the Eleventh Congress of the European Society for Research in Mathematics Education (pp. 4373-4380). Freudenthal Group \& Freudenthal Institute; Utrecht University; ERME.

Inglis, M., Schukajlow, S., Van Dooren, W. \& Hannula, M. S. (2018). Replication in mathematics education. In E. Bergqvist, M. Österholm, C. Granberg \& L. Sumpter (Eds.), Proceedings of the 42nd Conference of the International Group for the Psychology of Mathematics Education, Vol. 1 (pp. 195-196). PME.

Jacobson, E. \& Simpson, A. (2019). Prospective elementary teachers' conceptions of multidigit number: Exemplifying a replication framework for mathematics education. Mathematics Education Research Journal, 31(1), 67-88. https://doi.org/10.1007/ s13394-018-0242-X.

Jankvist, U. T., Aguilar, M. S., Ärlebäck, J. B. \& Wæge, K. (2017). Introduction to the papers of TWG23: Implementation of research findings in mathematics education. In T. Dooley \& G. Gueudet (Eds.), Proceedings of the Tenth Congress of the European Society for Research in Mathematics Education (pp. 3769-3775). DCU Institute of Education; ERME.

Jankvist, U. T., Aguilar, M. S., Dreyøe, J. \& Misfeldt, M. (2019). Adapting implementation research frameworks for mathematics education. In U. T. Jankvist, M. van den Heuvel-Panhuizen \& M. Veldhuis (Eds.), Proceedings of the Eleventh Congress of the European Society for Research in Mathematics Education (pp. 44054412). Freudenthal Group \& Freudenthal Institute; Utrecht University; ERME.

Jankvist, U. T., Gregersen, R. M. \& Lauridsen, S. D. (2021). Illustrating the need for a 'Theory of Change' in implementation processes. ZDM Mathematics Education. https://doi.org/10.1007/s11858-021-01238-1.

Koichu, B., Aguilar, M. S. \& Misfeldt, M. (Eds.). (2021). Implementation and implementability of mathematics education research [Special issue]. ZDM Mathematics Education, 53(5).

Krainer, K. (2014). Teachers as stakeholders in mathematics education research. The Mathematics Enthusiast, 11(1), 49-6o.

Levine, D. U. \& Cooper, E. J. (1991). The change process and its implications in teaching thinking. In L. Idol \& B. F. Jones (Eds.), Educational values and cognitive instruction: Implications for reform (pp. 387-408). Routledge. https://doi.org/ $10.4324 / 9781315044392$. 
Maass, K., Cobb, P., Krainer, K. \& Potari, D. (Eds.). (2019). Different ways to implement innovative teaching approaches at scale [Special issue]. Educational Studies in Mathematics, 102(3).

Melhuish, K. \& Thanheiser, E. (2018). Reframing replication studies as studies of generalizability: A response to critiques of the nature and necessity of replication.Journal for Research in Mathematics Education, 49(1), 104-110. https://doi.org/10.5951/ jresematheduc.49.1.0104.

Nilsen, P. (2015). Making sense of implementation theories, models and frameworks. Implementation Science, 10, Article number 53. https://doi.org/10.1186/s13012-015 -0242-0.

Niss, M. (1996). Mathematics in society. In R. Biehler, R. W. Scholz, R. Sträßer \& B. Winkelmann (Eds.), Didactics of mathematics as a scientific discipline (pp. $3^{6} 7-$ 378). Kluwer.

Peterson, J. C. (1971, February 4-7). Effect of an advanced organizer, a post organizer, or knowledge of the behavioral objective on achievement and retention of a mathematical concept [Paper presentation]. Annual meeting of the American Educational Research Association, New York, NY, United States.

Peterson, J. C., Thomas, H. L., Lovett, C. J. \& Bright, G. W. (1973). The effect of organizers and knowledge of behavioral objectives on learning a mathematical concept. Journal for Research in Mathematics Education, 4(2), 76-84. https://doi.org/10.5951/ jresematheduc.4.2.0076.

Roesken-Winter, B., Stahnke, R., Prediger, S. \& Gasteiger, H. (2021). Towards a research base for implementation strategies addressing mathematics teachers and facilitators. ZDM Mathematics Education. https://doi.org/10.1007/s11858-021-01220-x.

Rogers, E. M. (1962). Diffusion of innovations. Free Press of Glencoe.

Schoenfeld, A. H. (2016). Research in mathematics education. Review of Research in Education, 40(1), 497-528. https://doi.org/10.3102/oo91732X16658650.

Schoenfeld, A. H. (2018). On replications. Journal for Research in Mathematics Education, 49(1), 91-97. https://doi.org/10.5951/jresematheduc.49.1.oo91.

Sierpinska, A. \& Kilpatrick, J. (Eds.). (1998). Mathematics education as a research domain: A search for identity. Kluwer.

Star, J. R. (2018). When and why replication studies should be published: Guidelines for mathematics education research journals. Journal for Research in Mathematics Education, 49(1), 98-103. https://doi.org/10.5951/jresematheduc.49.1.oo98.

Star, J. R. (2021). In pursuit of a replication culture in mathematics education. Implementation and Replication Studies in Mathematics Education, 1(1), 53-76. https://doi.org/10.1163/26670127-12341237.

Star, J. R., Lynch, K. \& Perova, N. (2011). Using video to improve mathematics' teachers' abilities to attend to classroom features: A replication study. In M. G. Sherin, 
V. R. Jacobs \& R. A. Philipp (Eds.), Mathematics teachers' noticing: Seeing through teachers' eyes (pp.117-133). Routledge.

Thanheiser, E. (2018). The effects of preservice elementary school teachers' accurate self-assessments in the context of whole number.Journalfor Research in Mathematics Education, 49(1), 39-56. https://doi.org/10.5951/jresematheduc.49.1.oo39.

Torbeyns, J., Peters, G., De Smedt, B., Ghesquière, P. \& Verschaffel, L. (2018). Subtraction by addition strategy use in children of varying mathematical achievement level: A choice/no-choice study. Journal of Numerical Cognition, 4(1), 215-234. https://doi .org/10.5964/jnc.v4i1.77.

Van Der Auwera, S., Mathys, L., De Smedt, B., Torbeyns, J. \& Verschaffel, L. (2021). Task-based and subject-based adaptivity of upper elementary school children's choices for subtraction by addition when solving symbolic multi-digit subtractions: a choice/no-choice replication study involving two choice conditions. Implementation and Replication Studies in Mathematics Education, 1(1), 111-138. https://doi.org/10.1163/26670127-12341241. 